\title{
Decarbonylative olefination of aldehydes to alkenes
}

\author{
Diana Ainembabazi, Christopher Reid, Amanda Chen, Jakub Kostal, Adelina Voutchkova-Kostal
}

Chemistry Department, the George Washington University, $80022^{\text {nd }}$ St NW, Washington D.C. 20910

\section{Supporting Information Placeholder}

ABSTRACT: New atom-economical alternatives to Wittig chemistry are needed construct olefins from carbonyl complexes, but none have been developed to-date. Here we report an atom-economical olefination of carbonyls via aldol-decarbonylative coupling of aldehydes using robust and recyclable supported $\mathrm{Pd}$ catalysts, producing only $\mathrm{CO}$ and $\mathrm{H}_{2} \mathrm{O}$ as waste. The reaction accommodates homocoupling of aldehydes with an a $\alpha$-methylene groups, as well as heterocoupling. Computations provide insight into the selectivity of the reaction. The tandem aldol-decarbonylation reaction opens the door to exploration of new carbonyl reactivity to construct olefins.

The carbonyl olefination of ketones or aldehydes by phosphorous ylids, discovered by Wittig (Scheme 1a), has been a cornerstone of modern synthesis due to its utility and reliability. ${ }^{1-2}$ However, the utility of the chemistry is hindered by the need to pre-form phosphorous ylids and the production of stoichiometric waste, necessitating the development of more atom-economical alternatives. Recently we reported the high activity of heterogeneous catalysts based on Pd-doped hydrotalcites (Pd-HTs) for selective decarbonylation of aldehydes. ${ }^{4}$ In the course of this study we observed that $\alpha, \beta$-unsaturated aldehydes decarbonylate faster than aromatic and saturated aliphatic aldehydes. Given that hydortalcites, composed of metal hydroxide sheets sandwiched by anions and water, have basic sites, they can promote aldol condensation. ${ }^{7-8} \mathrm{We}$ thus anticipated that aliphatic aldehydes would undergo competing aldol condensation to form forms $\alpha, \beta$-unsaturated aldehydes, which can undergo further decarbonylation to form alkenes (Scheme 1a and 2). Thus, we set out to develop a practical catalytic process for decarbonylative coupling of carbonyls to selectively afford alkenes through decarbonylative homo- and hetero-coupling.

Catalysts for tandem aldol condensation-decarbonylation should be bifunctional, consisting of catalytic sites effective for both steps. It would be advantageous to be able to tune the activity of both sites independently in order to optimize selectivity for different carbonyl substrates.

\section{Scheme 1}

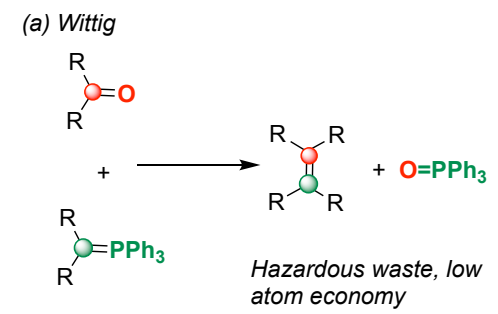

(b) This work

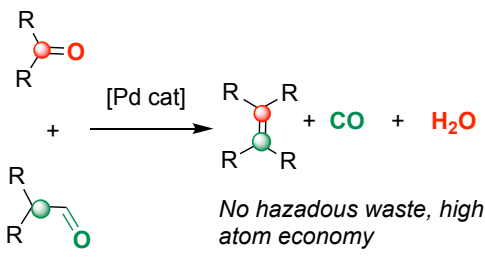

Given that the aldol condensation is catalyzed by either acid or base sites, we thus considered hydrotalcites, $\mathrm{MgO}$, $\mathrm{Al}_{2} \mathrm{O}_{3}$ and silica as supports. However, the electronic nature of the support will also affect the activity of the Pd phase, which catalyzes the decarbonylation. ${ }^{9}{ }^{10}$ In order to explore the potential of optimizing both steps, we synthesized and screened Pd-HT, Pd- $\mathrm{Al}_{2} \mathrm{O}_{3}, \mathrm{Pd}-\mathrm{SiO}_{2}$, and Pd$\mathrm{MgO}$ for the reaction in Scheme 2.

Initial findings showed that Pd-HTs facilitates the conversion of neat aldehydes with $\alpha$-methylene groups to the $\alpha, \beta$-unsaturated carbonyls, which decarbonylate to afford internal alkenes (Scheme 2). The reactions require low $\mathrm{Pd}$ loading $(0.1 \mathrm{~mol} \% \mathrm{Pd})$ and proceed at $150{ }^{\circ} \mathrm{C}$ or above using microwave and conventional heating. Heptanal thus afforded (E)-tridec-6-ene, an olefin with (2n-1) carbons and some respective aldol intermediates 2 and 3 (Scheme 2).

\section{Scheme 2}

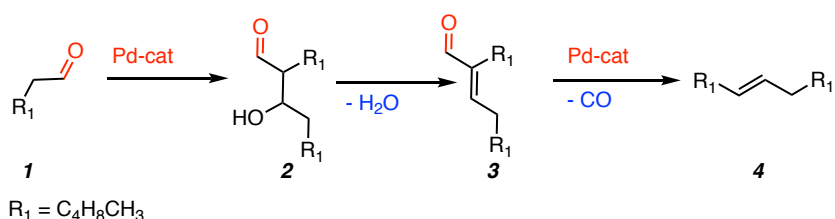




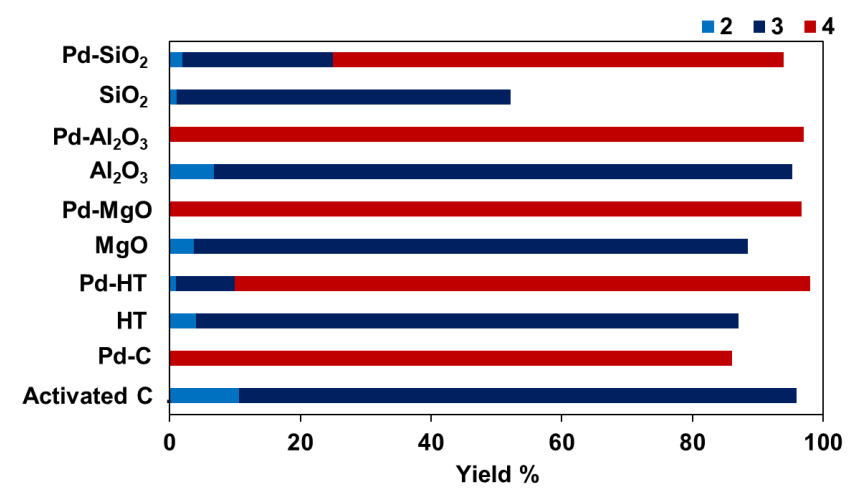

Figure 1. Product distribution of Pd catalysts and supports in decarbonylative olefination of heptanal at $180^{\circ} \mathrm{C}$. (Conditions: $0.1 \mathrm{~mol} \% \mathrm{Pd}, 8 \mathrm{hr}$ ).

The activity of five supported Pd catalysts were examined with heptanal as model substrate at 150 and $180^{\circ} \mathrm{C}$, (Figure 1 and ESI S1). The activity of the supports was tested as a control in order to distinguish the activity for aldol vs decarbonylation. Consistent with our initial hypothesis, the supports showed good to excellent activity for aldol condensation, but only the Pd catalysts afforded alkene product $(4$, Figure 1$)$.

At $150{ }^{\circ} \mathrm{C} \mathrm{Pd}-\mathrm{Al}_{2} \mathrm{O}_{3}$ afforded highest yield of $4(35 \%)$, followed by Pd-C with $20 \%$ in 8 h (ESI Figure S1). However, the overall conversion of aldehyde with $\mathrm{Pd} / \mathrm{C}$ was the lowest of all the catalysts tested, suggesting it was a poor catalyst for the aldol condensation. In contrast, Pd$\mathrm{MgO}$ and Pd-HT afforded full conversion of substrate, but only $10-15 \%$ yield of the alkene. The trend for activity for aldol condensation was thus established as $\mathrm{MgO}>\mathrm{HT}>$ $\mathrm{Al}_{2} \mathrm{O}_{3}>$ activated carbon $>\mathrm{SiO}_{2}$; and for decarbonylation as: $\mathrm{Pd}-\mathrm{Al}_{2} \mathrm{O}_{3}>\mathrm{Pd}-\mathrm{C}>\mathrm{Pd}-\mathrm{HT}>\mathrm{Pd}-\mathrm{MgO}>\mathrm{Pd}-\mathrm{SiO}_{2}$. At $180{ }^{\circ} \mathrm{C}$ quantitative yields of alkene 4 could be obtained with $\mathrm{Pd}-\mathrm{Pd}-\mathrm{Al}_{2} \mathrm{O}_{3}$, Pd-HT and $\mathrm{Pd}-\mathrm{MgO}$ in only 8 hours, while $\mathrm{Pd}-\mathrm{C}$ and $\mathrm{Pd}-\mathrm{SiO}_{2}$ afforded over 70 and $82 \%$ respectively (Figure 1).

Reaction time courses of the three most promising catalysts revealed further details about the relative aldol vs decarbonylation activity. At $100{ }^{\circ} \mathrm{C}$, no decarbonylation is observed, and aldol activity follows the trend $\mathrm{Pd}-\mathrm{HT} \sim$

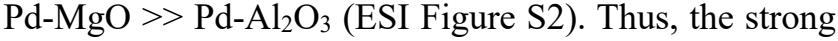
basic sites on $\mathrm{MgO}$ and $\mathrm{HT}$ are significantly more effective at facilitating aldol condensation than the Lewis acidic sites of $\mathrm{Al}_{2} \mathrm{O}_{3}$. At $150{ }^{\circ} \mathrm{C}$ decarbonylation yields range from $38-78 \%$ of 4 in $24 \mathrm{hr}$, discerning the activity trend for decarbonylation: $\mathrm{Pd}-\mathrm{Al}_{2} \mathrm{O}_{3}>\mathrm{Pd}-\mathrm{HT}>\mathrm{Pd}-\mathrm{MgO}$ (ESI Figure S3), while at $180{ }^{\circ} \mathrm{C}$ decarbonylation is so rapid that no intermediate 3 is observed at the end of the reaction (ESI Figure S4). Decarbonylation rate is thus rate-determining, and is sensitive to temperature in the range studied. Further reactions were explored using $\mathrm{Pd}-$ $\mathrm{Al}_{2} \mathrm{O}_{3}$ as the most active catalyst.

Curiously, we observation that the configuration of aldol intermediate 3 is cis w.r.t. R-groups, while alkene 4 is a trans alkene (ESI Figure S5). Based on Zimmerman-
Traxler 6-membered transition state for the alkylation of the enolate, trans configuration of 3 suggests it was derived from a cis enolate. The latter could be preferred when the acid/base sites are immobilized on a solid support. The trans geometry of 4 indicates that the catalyst facilitates both isomerization and decarbonylation of 3 . As further evidence for the latter, we find that $\alpha$ methylcinnamaldehyde (cis w.r.t. the R-groups) affords a 1:6 ratio of cis:trans propylbenzene in 8 hours of reaction with $\mathrm{Pd}-\mathrm{Al}_{2} \mathrm{O}_{3}$, and complete conversion to the trans product in 24 hours (ESI Figure S6). This is consistent with the assertion that the catalyst facilitates both decarbonylation and isomerization to the thermodynamic alkene isomer. No double bond migration was observed.

Scheme 3

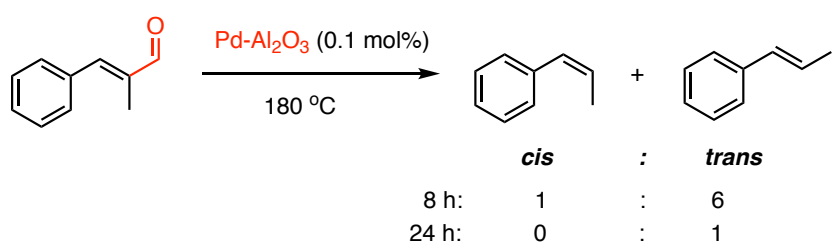

We briefly explored the substrate scope of the decarbonylative olefination. Aliphatic aldehydes afford excellent yields (Table 1, entries 1 and 2), while branched aldehydes react more slowly (entries 4 and 5). The latter is due to slower aldol for hindered secondary aldehydes, as evidenced by no unreacted aldol intermediates after 8 hours. In the case of phenylacetaldehyde, the lower yield $(40 \%)$ is due to the fast decarbonylation of the substrate relative to aldol condensation, affording toluene. The latter emphasizes that obtaining olefin selectively requires balancing rates of three independent reactions: decarbonylation of initial substrate, aldol and decarbonylation of aldol condensation product.

Table 1. Substrate scope for decarboxylative olefination.
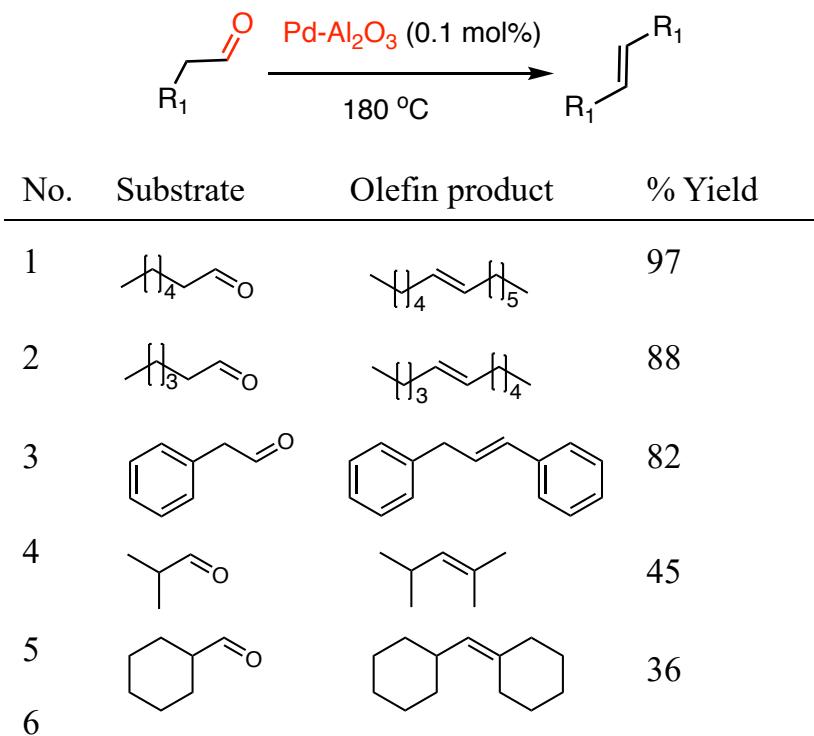

Conditions: $14 \mathrm{mmol}$ substrate, $0.1 \mathrm{~mol} \% \mathrm{Pd}-\mathrm{Al}_{2} \mathrm{O}_{3}, 180$ ${ }^{\circ} \mathrm{C}, 8 \mathrm{~h}$. 
We also explored whether this reaction can be optimized in the heterocoupling reactions of two aldehydes. Selectivity for heterocoupling is favored by combining an enolizable aldehyde with a non-enolizable one, such as benzaldehyde. When the reaction was performed using the conditions optimized for homocoupling, selectivity for the desired heterocoupled olefin was low due to rapid decarbonylation of the non-enolizable aldehyde relative to aldol condensation. To increase selectivity for the cross-aldol condensation we introduced a more effective solid aldol catalyst than alumina - hydrotalcite (HT). By using only HT in the first stage of the reaction one cabn pre-form the hetero-aldol product, which is then decarbonylated by $\mathrm{Pd}-\mathrm{Al}_{2} \mathrm{O}_{3}$. This resulted in high selectivity and yield of the desired olefin (79\% yield in 6 hours for furfural and heptanal).

The yields obtained for the heterocoupling of a selection of substrates are summarized in Table 2. All the substrates used afforded full conversion, and good to excellent yields of desired olefin, although competing homocoupling of heptanal decreased selectivity. The selectivity for heterocoupling is limited by the aldol step, which is affected by the relative reactivity of the non-enolizable aldehydes. For example, furfural carbonyl carbon is more electrophilic than that of benzene, and thus more reactive as aldol electrophile (crudely approximated by the Mulliken charges, ESI Table S1??). However, synthetic conditions can be further optimized to improve selectivity for the hetero aldol.

Table 2. Substrate scope for heterocoupling of aldehydes with heptanal.
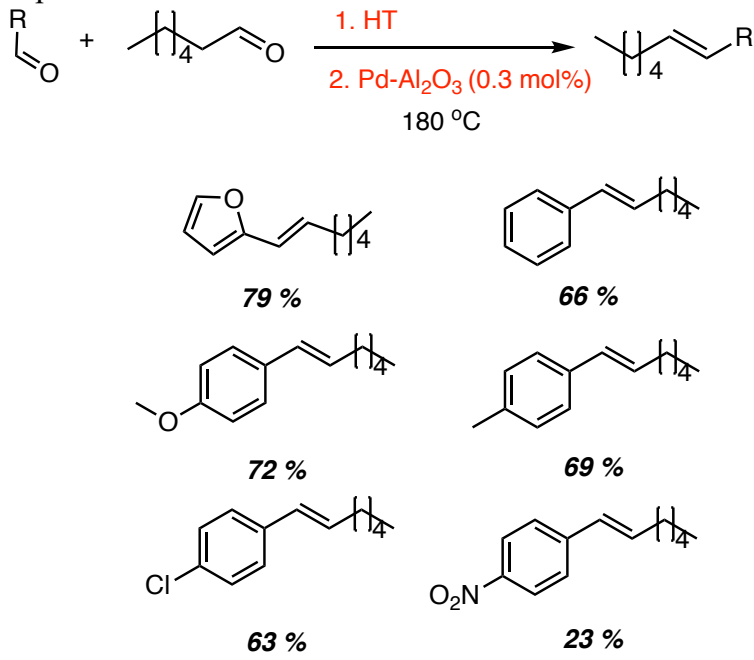

Conditions: $1.7 \mathrm{mmol}$ heptanal, $10 \mathrm{mmol}$ aldehyde, 50 mg HT, $180^{\circ} \mathrm{C}, 2 \mathrm{~h} ; 2$. Add $0.3 \mathrm{~mol} \%, \mathrm{Pd}-\mathrm{Al}_{2} \mathrm{O}_{3}, 180^{\circ} \mathrm{C}, 6$ h.

Reaction thermodynamics. We briefly explored the relative thermodynamic stability of the intermediates and products in the reaction with heptanal (Scheme 2). All calculations were carried out with the PM7 semiempirical method in gas phase using the Gaussian 16 software. ${ }^{1}$
Geometries were fully optimized, and all minima were verified to have to imaginary vibrational frequencies. Free energies were evaluated at $298 \mathrm{~K}$. Computational results indicate that while initial aldol addition is 2.9 $\mathrm{kcal} / \mathrm{mol}$ uphill, the aldol condensation product is thermodynamically favorable $\left(\Delta \mathrm{G}_{\mathrm{rxn}}=-3.9\right.$ and $-4.0 \mathrm{kcal} / \mathrm{mol} \mathrm{re}-$ spectively for trans and cis $\alpha, \beta$-unsaturated carbonyl) w.r.t. heptanal (Figure 1). The subsequent decarbonylation to the cis-olefin is almost thermoneutral $\quad(-0.5$ $\mathrm{kcal} / \mathrm{mol}$ ), but the isomerization to the trans-olefin (4) drives $\Delta \mathrm{G}_{\mathrm{rxn}}$ to be slightly more favorable $(-1.3 \mathrm{kcal} / \mathrm{mol})$, bringing the overall $\Delta \mathrm{G}_{\mathrm{rxn}}$ of the two-step process to -5.2 $\mathrm{kcal} / \mathrm{mol}$ (vs. $-4.4 \mathrm{kcal} / \mathrm{mol}$ for the cis-olefin). These calculations are consistent with the experimental observation of the trans-olefin product. Furthermore, they suggest that while the reaction is slightly thermodynamically favorable, it is close enough to thermoneutral to potentially allow for reversibility under appropriate conditions.

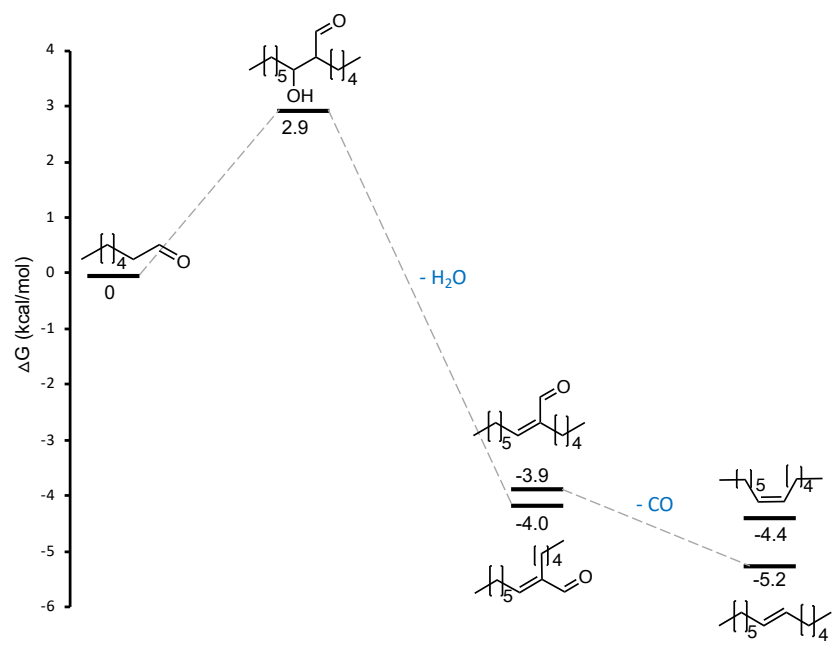

Figure 1. Free energy diagram for decarbonylative olefination of heptanal (Scheme 2).

The recyclability of the $\mathrm{Pd}-\mathrm{Al}_{2} \mathrm{O}_{3}$ was explored for this reaction with heptanal. The catalyst was separated from after reaction centrifugation, washing and drying, and reused. The yields of products obtained over 9 cycles indicate that the catalyst retaines activity over 9 cycles (ESI Figure S7), with a small decrease in selectivity remaining 93\% - 98\% after cycle 4 . Elemengtal analysis of the catalyst after 9 cycles shows negligible loss of $\mathrm{Al}$ (within the standard error of the as-prepared catalysts), but a $23 \mathrm{wt} \%$ decrease in Pd, suggesting this could be a reason for the small drop in selectivity.

To investigate whether $\mathrm{Pd}-\mathrm{Al}_{2} \mathrm{O}_{3}$ was operationally heterogeneous in this reaction, we applied a combination of hot filtration, selective poisoning, and mercury poisoning tests. Hot filtration was performed by sampling a portion of the reaction mixture after $3 \mathrm{~h}$ of reaction and passing the mixture through a hot frit $(2 \mu \mathrm{m})$. After $5 \mathrm{~h}$ further reaction, the concentration of olefin 4 did not change 
significantly from the time of filtration (ESI Figure S8a), suggesting that the catalytic species are absent from the filtrate. The catalytic activity was also completely quenched by mercury poisoning, which amalgamates with supported palladium. ${ }^{12}$ The reaction produced product 3 as the only product and no product 4 was observed. (ESI Figure S8b). However, catalytic activity was also quenched by Quadrapure-TU, ${ }^{13-14}$ a known scavenger for soluble Pd complexes and nanoparticles. ${ }^{15}$ The latter suggests catalytic involvement of both heterogeneous and soluble Pd species in this multi-step process. The presence of complex equilibrium between surface-bound and soluble Pd species is also likely, which is not atypical of heterogeneous catalysis in the condensed phase. The catalyst behavior warrants future operando spectroscopic studies to further interrogate the nature of the catalytic species.

\section{Conclusion}

Here we report a new transformation decarboxylative olefination of aldehydes, proceeding via aldol and decarbonylation. The reaction is effectively facilitated by $\mathrm{Pd}-$ $\mathrm{Al}_{2} \mathrm{O}_{3}$ as decarbonylation catalyst, and rehydrated hydrotalcite as the optimized aldol catalyst. The reaction has been optimized for both homocoupling and heterocoupling of aldehydes. The catalyst is recyclable, retained its activity over 9 cycles with minor decrease in selectivity after. Poisoning experiments implicate involvement of surface-bound and soluble Pd species.

obtaining olefin selectively requires balancing rates of three independent reactions: decarbonylation of initial substrate, aldol and decarbonylation of aldol condensation product.

\section{ASSOCIATED CONTENT}

Supporting Information is available detailing catalyst synthesis and characterization, additional figures and NMR characterization of products.

\section{Funding Sources}

We thank NSF CBET for support of this work (award 1805080)

\section{ACKNOWLEDGMENT}

We thank the Material Institute at GWU and Surface Analysis Center at University of Maryland for use of instrumentation in catalyst characterization.

\section{REFERENCES}

1. Hoffmann, R. W., Wittig and His Accomplishments: Still Relevant Beyond His 100th Birthday. Angewandte Chemie International Edition 2001, 40 (8), 1411-1416.

2. Sha, Q.; Wei, Y., Copper(I)-Catalyzed Wittig Olefination Reactions of N-Tosylhydrazones with Trifluoromethylketones. ChemCatChem 2014, 6 (1), 131-134.

3. Inhoffen, H. H.; Kath, J. F.; Brückner, K., Partialsynthese einer „trans”-Vitamin D2-Verbindung mit Hilfe der Reaktion von Wittig. Angewandte Chemie 1955, 67 (9-10), 276-276.

4. An, N.; Ainembabazi, D.; Samudrala, K.; Reid, C.; Wilson, K.; Lee, A. F.; Voutchkova, A., Microwave-assisted decarbonylation of biomass-derived aldehydes using Pd-doped hydrotalcites. Submitted to ChemSusChem 2019.

5. $\quad$ Evans, D. G.; Slade, R. C. T., Structural aspects of layered double hydroxides. In Layered Double Hydroxides, Duan, X.; Evans, D. G., Eds. Springer-Verlag Berlin: Berlin, 2006; Vol. 119, pp 1-87.

6. $\quad$ Benício, L. P. F.; Silva, R. A.; Lopes, J. A.; Eulálio, D.; Santos, R. M. M. d.; Aquino, L. A. d.; Vergütz, L.; Novais, R. F.; Costa, L. M. d.; Pinto, F. G.; Tronto, J., LAYERED DOUBLE HYDROXIDES: NANOMATERIALS FOR APPLICATIONS IN AGRICULTURE. Revista Brasileira de Ciência do Solo 2015, 39 (1), 1-13.

$7 . \quad$ Roelofs, J. C. A. A.; Lensveld, D. J.; van Dillen, A. J.; de Jong, K. P., On the Structure of Activated Hydrotalcites as Solid Base Catalysts for Liquid-Phase Aldol Condensation. Journal of Catalysis 2001, 203 (1), 184-191.

8. Tichit, D.; Lutic, D.; Coq, B.; Durand, R.; Teissier, R., The aldol condensation of acetaldehyde and heptanal on hydrotalcite-type catalysts. Journal of Catalysis 2003, 219 (1), 167-175.

9. Lejemble, P.; Gaset, A.; Kalck, P., From Biomass to Furan through Decarbonylation of Furfural under Mild Conditions. Biomass 1984, 4 (4), 263-274.

10. Meng, Q. W.; Qiu, C. W.; Ding, G. Q.; Cui, J. L.; Zhu, Y. L.; $\mathrm{Li}$, Y. W., Role of alkali earth metals over Pd/A12O3 for decarbonylation of 5-hydroxymethylfurfural. Catal Sci Technol 2016, 6 (12), 4377-4388.

11. Tayade, K. N.; Mishra, M., A study on factors influencing cross and self product selectivity in aldol condensation over propylsulfonic acid functionalized silica. Catalysis Science \& Technology 2013, 3 (5), 1288-1300.

12. Lee, A. F.; Ellis, P. J.; Fairlamb, I. J. S.; Wilson, K., Surface catalysed Suzuki-Miyaura cross-coupling by Pd nanoparticles: an operando XAS study. Dalton T 2010, 39 (43), 10473-10482.

13. Richardson, J. M.; Jones, C. W., Poly(4-vinylpyridine) and Quadrapure TU as selective poisons for soluble catalytic species in palladium-catalyzed coupling reactions - Application to leaching from polymer-entrapped palladium. Adv. Synth. Catal. 2006, 348 (10-11), $1207-$ 1216.

14. Richardson, J. M.; Jones, C. W., Strong evidence of solutionphase catalysis associated with palladium leaching from immobilized thiols during Heck and Suzuki coupling of aryl iodides, bromides, and chlorides. J. Catal. 2007, 251 (1), 80-93.

15. Lee, A. F.; Ellis, P. J.; Fairlamb, I. J. S.; Wilson, K., Surface catalysed Suzuki-Miyaura cross-coupling by Pd nanoparticles: an operando XAS study. Dalton Transactions 2010, 39 (43), 10473-10482. 